\title{
Research on Enterprise Flat Management Mode under the Network Economy circumstance
}

\author{
Yuting Zhao ${ }^{1, \text { a }}$ \\ ${ }^{1}$ Harbin University, Harbin, Heilongjiang province, Zip code 150086, China
}

Keywords: Enterprise Management; Flat Management Mode; Network Economy Circumstance

\begin{abstract}
With the continuous improvement of the network environmental circumstance, the enterprise is expected to exchange the information rapidly and effectively. Based on this actual background, the enterprise flat mode has been researched in this study, to replace the traditional pyramid management mode. As referred to the definition of the enterprise flat mode, the "five targets" mode is presented in this study, based on which the enterprise manager level can enlarge the span of control, decrease the manage steps and plan the enterprise sources to achieve the rapid and efficient management.
\end{abstract}

\section{Introduction}

With the continuous improvement of the network environmental circumstance, the information exchange between the upper levels and lower levels becomes more and more prompt, which makes the enterprise managers can generate coping strategy based on the environmental variation [1]. Under this circumstance, the fluent instruction transmission makes the middle management level become less important, and the enterprise functional departments intersection and merge becomes more and more widespread [2]. As a result, the enterprise organizational structure becomes more and more flat, and the flat management mode is the inevitable for the enterprise development [3].

Based on the enterprise development process, the organization reform is the integration of process, organization, manpower reform and the innovate application of information technology, which is reflected by some soft factors like staff's interrelationship [4], value, motivation and so on. As a result, the development of network economy promotes enterprises to redesign the traditional pyramid multi-level organization structure, and to strengthen information exchange and the merge of different departments, which can raise the enterprise management level further [5].

The enterprise organizational activities contain the capital flow, information flow and the affair flow, all of which requires the enterprises to work with high efficiency and make rapid response to the rapidly changing internal and external environment [6]. The network economy era has many notable features include more and more detailed division of labor and more and increasingly rapid development speed, which requires the enterprises to make rapid response to the environmental variation. The enterprise management efficiency depends on the network economical system perfection level, and the requirements for the staff's quality become more and more strict [7]. As a result, the development of network economy would promote the enterprise organization reform greatly, and the improvement in organization operational efficiency and response speed is inevitable requirement for the enterprise's future development. Under this background, the enterprise organization structure flexibility and efficiency need to be improved constantly[8], to make the enterprises adapt to the market variation more flexibly and make the communication between different departments more convenient.

The rapid development of network economy provides more efficient communication way for enterprise's management and operation, a more stable platform for enterprise's internal and external information sharing, and more solution for the enterprise's internal business process reform [9]. As a result, the network economy is usually regarded as the enabler and promoter for the enterprise's reform. However, the enterprise's reform not only depends on the rapid development of the network 
economy, but also a series of soft factors such as enterprise culture and the staff role awareness [10]. The simple automation is not enough for the reform in the enterprise operational process, and the form of operation, coordination mechanism as well as the culture atmosphere are the fundamental guarantees for the expected process performance [11].

\section{Enterprise Flat Management Mode}

The enterprise flat management mode is based on the enterprise's practical situation to remove the unnecessary management level existing in the pyramid management mode, which aims to improve the administrative efficiency by enlarging span of control, braking the boundaries between different departments and concentrating efforts to solve difficulties [12]. Based on the aforementioned flat management mode concept, the enterprise flat management "five targets" mode is presented in this study, based on which the enterprise manager level can enlarge the span of control, decrease the manage steps and plan the enterprise sources to achieve the rapid and efficient management mode. The schematic diagram of the enterprise flat management "five targets" mode is shown in Fig.1:

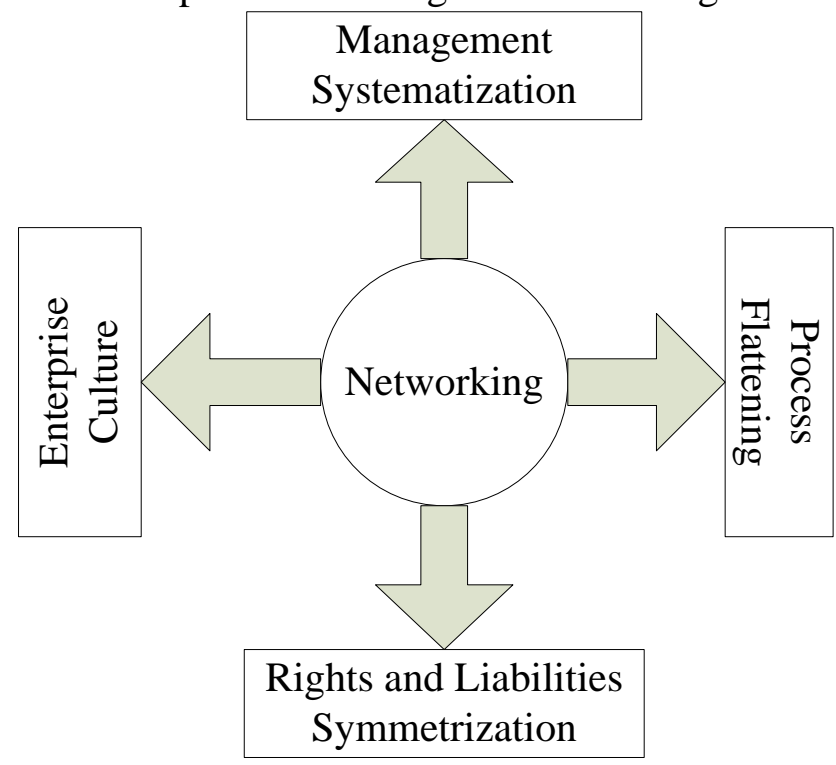

Fig.1. Flat management "five targets" mode

Management Systematization. The pyramid feudal hierarchy has bounded the managements' thinking for a long period, and most middle managers undertake less liabilities and risks under the strict pyramid management mode. As a result, the middle manager usually hinder the implement of the ernterprise flat management mode, who are the people with vested interests. Based on this current status, breaking the original middle management level is unavoidable for implementing the flat management, which can be helpful fot the enterprises to adapt to the market variation based on the optimized systematic structure, and form the flattening management system concept further [13].

Process Flattening. In the network economic era, it is necessary for the enterprises to make rapid reponse to the internal and external enviromental variation, which not only depends on the flattening organizational structure, but also the flattening business process [14]. In other words, the enterprise flat management means that each post would acquire a score of the management process, based on which the staff can konw what to do next immediately. The enterprise management process flattening design should be based on the enterprise's overall business goals and the principle of making the process as simple as possible, to generate the less management positions, and to define the concise operation process of each management position. Based on this principle, the optimized working process should be implemented, and the corresponding business can be surpervised.

Rights and Liabilities Symmetrization. The flattening is one of the mainstream ways for the enterprise organization reform in the network economy era, and the features of the flattening include 
less organization levels and larger organization management span, which can avoid the generation of some problems such as dull reaction and bureaucracy, to make the enterprises respond to the market variation better. However, the traditional centralized management style makes the liabilities and rights undertaken by enterprises are extremely asymmetric. With respect to many enterprises' organization structure reform, even if the vertical management levels are decreased, the transverse functional departments and the original duty boundaries make the effect of organization reform reduced greatly, and the staffs' belief in the organization reform can even be influenced greatly [15]. Therefore, the flattening management must be achieved by the way of controlled decentralization, namely the management style that the decentralization is prior and the centralization is lower. The goal of decentralization is to make the simplified management levels acquire the independent decision-making right and management right, and to encourage subordinates undertake more liabilities to achieve the expected business targets. The goal of centralization is to achieve real time monitoring for the each department, and make correction once the process and decision are not implemented strictly, which can be helpful for adjusting some local deviations. Based on the aforementioned analysis, the enterprise can truly achieve the rights and liabilities symmetrization and staff s can give full play to their initiative.

Enterprise Culture. The excellent enterprise culture can generate favorable enterprise environment, which can improve staffs' cultural literacy and moral standard to form the cohesion, centripetal force and constraining force, and therfoe the enterprise culture is indispensable spirit power. In the flat management, the enterprise's culture generation and improvement are extremely important, because selecting and appointing cadres is a matter of primary, which is based on the constructed enterprise culture.

Networking. In the era of network economy, the market changes rapidly and the chance fleets easily, which requires the enterprise to make response rapidly. As a result, the enterprise reform has to depend on the development of Internet technology, which can help enterprises integrate the internal sources and analyze the market's variation. Based on this development, the enterprise's instructions can pass to each staff with different levels, and it can make the direct and indirect management activities more efficient.

\section{Summary}

The enterprise management risk constantly changes with the development of network economy, which has shown different hazards in different periods. As a result, it is necessary for the enterprise managers to transform the enterprise management from traditional pyramid management mode to flat management mode. Based on this background, this study focuses on the risk environmental factors in the process of analyzing the enterprise managemenrt risk, where the enterprise managemenrt risk is divided into two groups of the managemenrt risks caused by the internal and external environmental factors. Based on the definition of the enterprise flat mode, the "five targets" management mode is derived at first, based on which the enterprise manager level can enlarge the span of control, decrease the manage steps and plan the enterprise sources to achieve the rapid and efficient management mode. In general, the current status of enterprise management risk has been analyzed in detail in this study, and a novel enterprise management mode has been presented to replace the traditional pyramid management mode, which are both significant for the enterprise risk management under the Network Economy circumstance.

\section{Acknowledgement}

The authors are grateful for the support provided fort his study by the Heilongjiang provincial development and Reform Commission in 13th Five-Year planning project. 


\section{References}

[1] Lemons J F. Issue: Flat Management Short Article: Established Companies Flatten Structures[J]. 2017.

[2] Lemons J F. Issue: Flat Management Short Article: Consulting Firm Experiments with 'Holacracy'[J]. 2017.

[3] Englund H, Englund H, Gerdin J, et al. What can (not) a flat and local structuration ontology do for management accounting research? A comment on Coad, Jack and Kholeif[J]. Qualitative Research in Accounting \& Management, 2016, 13(2): 252-263.

[4] Putra N, Ariantara B, Pamungkas R A. Experimental investigation on performance of lithium-ion battery thermal management system using flat plate loop heat pipe for electric vehicle application[J]. Applied Thermal Engineering, 2016, 99: 784-789.

[5] XIE L, ZENG W. Campus Virtual Flat Management Applications and Research-based CRP[J]. Information Technology and Informatization, 2014, 1: 023.

[6] Ebrahimi M, Shafii M B, Bijarchi M A. Experimental investigation of the thermal management of flat-plate closed-loop pulsating heat pipes with interconnecting channels[J]. Applied Thermal Engineering, 2015, 90: 838-847.

[7] Stanciu C, Stanciu D. Reply to "Comments on “Optimum tilt angle for flat plate collectors all over the World-A declination dependence formula and comparisons of three solar radiation models”[Stanciu, C., Stanciu, D., Energy Conversion and Management 81, 133-143]"[J]. Energy Conversion and Management, 2015 (93): 450-451.

[8] Radcliff K E, Sidhu G D S, Kepler C K, et al. Complications of flat bed rest after incidental durotomy[J]. Clinical spine surgery, 2016, 29(7): 281-284.

[9] Lee S H, Seo T I, Jung S K, et al. A study about flat mirror type solar thermal generation system to independently supply electricity on water resources management system[J]. Journal of the Korea Academia-Industrial cooperation Society, 2015, 16(8): 5067-5073.

[10] Harris R H, Officer S J, Hill P A, et al. Can nitrogen fertiliser and nitrification inhibitor management influence $\mathrm{N} 2 \mathrm{O}$ losses from high rainfall cropping systems in South Eastern Australia?[J]. Nutrient cycling in agroecosystems, 2013, 2(95): 269-285.

[11] Colla V, Nastasi G, Maddaloni A, et al. Intelligent control station for improved quality management in flat steel production[J]. IFAC-PapersOnLine, 2016, 49(20): 226-231.

[12] Wurm E, Pellacani G, Longo C, et al. The value of reflectance confocal microscopy in diagnosis of flat pigmented facial lesions: a prospective study[J]. Journal of the European Academy of Dermatology and Venereology, 2017.

[13] Schillaci C, Saia S, Braun A, et al. Mapping of topsoil organic carbon in agro-ecosystems of a flat terrain area (Lombardy) by means of legacy soil data, climatic data and NDVI time series predictors with machine learning methods[C]//EGU General Assembly Conference Abstracts. 2017, 19: 19047.

[14] Van Assche G, Dignass A, Bokemeyer B, et al. Second European evidence-based consensus on the diagnosis and management of ulcerative colitis part 3: special situations[J]. Journal of Crohn's and Colitis, 2013, 7(1): 1-33.

[15] Maillé P, Tuffin B. Users facing volume-based and flat-rate-based charging schemes at the same time[C]//Network Operations and Management Symposium (LANOMS), 2015 Latin American. IEEE, 2015: 23-26. 